\title{
THE PROGRESS OF CAMOUFLAGE
}

$\mathrm{I}^{\mathrm{N}}$ NATURE of June 22, there appeared a leading article in which the camouflage organizations of Great Britain were severely criticized for not making sufficient use of scientific men and scientific principles.

As evidence of the way in which the scientific spirit is, however tardily, coming into its own in the conduct of the war, the following impressions of a visit to the headquarters of the Civil Defence Camouflage Organization may be of interest.

This is the largest central organization devoted to camouflage, and forms part of the Research and Experiments Department of the Ministry of Home Security, to whom Dr. R. E. Stradling is the chief adviser. The experimental work is under the direct supervision of Prof. W. E. Curtis, assisted by a technical staff which includes artists, engineers, architects, chemists, physicists, photographers, and a botanist. All the work is studied as an air problem. The sites and buildings to be camouflaged are first viewed and photographed from the air. If they are of major importance, a model is then made and camouflage applied to it. It is inspected in a special viewing room, where a turntable and a movable light provide varied conditions of illumination; and also out-of-doors from a greater distance. After the model has been, if necessary, corrected, and a colour photograph taken of it, the camouflage scheme is then applied to the actual site, which is then again viewed and photographed, this time in colour, from the air; and any final corrections required are then made. In the case of smaller buildings or those which offer less difficult problems, the model is dispensed with, and its place is taken by a two-dimensional sketch of the camouflage scheme.

One of the criticisms made in the earlier article was that biological principles were being largely disregarded. This certainly does not apply to the present work of the Civil Defence Camouflage Organization. What the biologist calls general resemblance, special resemblance, disruptive pattern, deflection, and mimicry are all now being employed as the situation dictates.

General resemblance is more commonly employed in military camouflage in the field, where mobile objects are coloured so as to be as inconspicuous as possible against a variety of surroundings. Special resemblance to particular natural objects is often extremely ingenious. Admirable methods of counterfeiting grass are now available, and artificial woods with 'sapless foliage' but permanent greenery spring up where required.
Sham buildings, worthy of a film set, may be used to disguise landmarks.

In biological mimicry of the typical or Batesian kind, a harmless organism evolves so as to counterfeit the appearance of one better protected against enemies than itself. The reverse is true in mimetic camouflage: an object of military importance, such as an armaments factory, is disguised to resemble a non-military objective. Some of these schemes are most successful.

In biological deflection, the attack of an enemy is drawn away by conspicuous pattern from a more vital to a less vital part of the body, or from a biologically more important individual (such as a brooding duck) to a less important one (such as the drake, the racial function of which is over for the year once he has fertilized the eggs). In a similar way, false targets may be employed in war to draw attack away from real ones: without giving away vital secrets, it may be said that some of the deflection methods now employed are both ingenious and effective.

Disruptive pattern, however, when all is said and done, is the most essential tool of camouflage for large stationary objects such as buildings ; and this is now being employed to extraordinarily good effect. One of the earlier criticisms was that the pattern used was on too small a scale to be effective against air attack, but this no longer holds, and remarkable illusions are produced.

Another criticism made in the earlier article was that structural methods were being neglected, and undue reliance placed on paint, which by itself is often helpless to disguise shadows and hard outlines. This was true to some extent during the early months of the War, but to-day (though not until after a struggle) various structural devices are being utilized on a large scale, and a special engineering section has been formed in the camouflage establishment to deal with the unfamiliar and troublesome problems involved in their proper use.

Yet another criticism was that the work was entrusted too exclusively to artists. The experience of the Civil Defence Camouflage Station is that artists are indispensable for design, both because of their gifts of observation and for their capacity to see and memorize a site in terms of colours and tones instead of in terms of objects of human significance, and also because of their technical knowledge as executants. But their work is carried out under the supervision of the 
physicist in charge, so that art is constantly guided and checked by seience.

It must not, however, be supposed that perfection, scientific or otherwise, yet reigns in the camouflage world. In the first place, the Civil Defence Station is only one, albeit the largest, of the various organizations dealing with the problem. In addition, there is a large amount of private property not regarded as of sufficient importance to justify official action. In practice, however, owners of such property are consulting the Station in increasing numbers, with the result that there will be fewer unscientific monstrosities such as the cooling cylinders, mentioned in NATURE of June 22, the white surface of which was adorned with naturalistic trees.

Not all the different organizations are as yet equally scientific or efficient, and in some cases, notably ships at sea, far too much use has been made of the anti-scientific principle of uniformity of colour and tone, which gives the most conspicuous possible pattern.

In addition it would appear that in some quarters camouflage has become a sort of fetish, implying the application of green and brown blotches of one or two feet in diameter, whatever the object to be disguised and whatever its surroundings. But here, too, the situation is improving.

Then, as may be imagined, co-ordination and central direction are difficult so long as we have numerous separate organizations which, starting independently, tend to preserve their independence. Something, however, has been done to remedy this, by means of a new co-ordinating committee; attached to the Civil Defence Camouflage Station, but containing representatives of other organizations, both official and non-official.
But the most important enemy of efficiency has been delay - delay between the completion of a scheme and the beginning of the application of paint to the actual building, delay which may involve several wasted months. In part this would appear to have been due to official regulations and methods of working, in part to carelessness or inefficiency on the part of the private firms the buildings of which are being camouflaged, or of the firms undertaking the actual camouflage.

Another trouble is the habit of regarding camouflage as something you put on to a building when it is completed. The notion that it would be much easier and cheaper, and much more likely to achieve really good disguise, if buildings were designed from the outset in relation to the problem of their camouflage, has scarcely entered the mind of authority or of builders. Buildings of the utmost regularity, and therefore extremely difficult to disguise, still continue to be erected, simply because that is the recognized pattern for buildings for that particular purpose.

Photographs of one of the few buildings which has been designed from the outset in co-operation with camouflage experts make one realize what could be achieved. The huge structure is part of the English landscape, complete with fields, woods, roads and hedges, and is as nearly indistinguishable as could be imagined.

The camouflage services inevitably suffer from the high cost of many of their schemes, the shortage of supplies, and the fact that camouflage is low on the list of priorities. It is clear, however, that in spite of a slow start, the art of camouflage has in the last six months gone far in utilizing scientific knowledge and scientific methods.

J. S. H.

\section{O B I T U A R I E S}

\section{Sir Harold Carpenter, F.R.S.}

SIR (Henry CoRT) Harold CARPENTER, professor of metallurgy in the Royal School of Mines, London, whose death at the age of sixty-five occurred on September 13, was regarded as the leader of the metallurgical profession in Great Britain. He came from a family which produced several distinguished men, and in view of his career it is particularly interesting that one of his great-great-grandfathers was Henry Cort, whose inventions did so much to establish the position of England at the head of the iron industry in the eighteenth and nineteenth centuries. Carpenter, however, was not originally trained as a metallurgist. He studied chemistry at Oxford and Leipzig, and became research fellow and demonstrator in Owens College, Manchester.
When the National Physical Laboratory was established in 1902, Carpenter was appointed to take charge of chemical and metallurgical work. The choice was fully justified by the production, in a very short time, of several important researches, the chief of which was the determination, with B. F. E. Keeling, of the range of solidification and the critical ranges of the iron-carbon alloys. Although much work has since been done on this system, the latest determination confirms the essential accuracy of their results, other investigators having been less successful in obtaining equilibrium. The aluminiumcopper system was examined with similar minute accuracy, while other papers dealt with the heat treatment of high-speed tool steels and with complex alloys of iron-a remarkable output for the early 